\title{
A INTERVENÇÃO (HUMANITÁRIA?) NO IRAQUE
}

\author{
Malu Maria de Lourdes Mendes PEREIRA ${ }^{1}$ \\ Wagner Saraiva Ferreira Lemgruber BOECHAT ${ }^{2}$ \\ Paulo Afonso Ribeiro DAHER JUNIOR ${ }^{3}$
}

Recebido em: 15/09/2015 - Aprovado em: 23/06/2016 - Disponibilizado em: 30/07/2016

\begin{abstract}
Resumo: A intervenção humanitária foi criada para ser um instrumento de ajuda entre os países. Seu objetivo era, e ainda é, socorrer países que estejam com problemas que afetem direitos humanos de sua população, por meio, até mesmo, do uso da força, quando necessário. Porém, nos últimos anos, vemos que este instrumento, que mitiga o conceito de soberania, tem sido usado para que um país, mais poderoso, intervenha em outros países, menos poderosos, com objetivos meramente econômicos. Para demonstrar o exposto será analisado o caso concreto do Iraque que sofreu intervenção, com a justificativa de ser humanitária, suas consequências para aquele país e será verificado se este foi o melhor caminho.
\end{abstract}

Palavras-chave: intervenção humanitária, Iraque, soberania mitigada, Estado Islâmico.

Abstract: humanitarian intervention was designed to be an instrument of aid between the countries. His aim was, and still is, help countries that have problems that affect the human rights of its people, through even the use of force when necessary. However, in recent years, we see that this instrument, which mitigates the concept of sovereignty, has been used for a country, more powerful, intervene in other countries, less powerful, with purely economic goals. To demonstrate the above will be analyzed the case of Iraq that suffered intervention, with the rationale being, humanitarian consequences for that country and will be verified that this was the best way.

Keywords: humanitarian intervention, Iraq, namely sovereignty, Islamic State.

\footnotetext{
${ }^{1}$ Auditora Fiscal da Receita Estadual (MG) e professora de Direito Administrativo e Direito Civil na Faculdade de Direito de São Lourenço/MG (UNISEPE). Graduada Direito e em Comunicação Social, pós-graduada e Mestre em Direito Constitucional pela Faculdade de Direito do Sul de Minas (FDSM). Também possui especializações em Direito Tributário, Direito do Estado, Direito Civil e Direito Notarial e Registral. É frequentadora dos cursos intensivos válidos para o doutorado em Direito Constitucional da Universidad de Buenos Aires, já tendo concluído os créditos. E-mail: malu_pereira@ig.com.br

${ }^{2}$ Advogado, consultor Ambiental, professor de Direito na Universidade Vale do Rio Verde e Faculdade de São Lourenço. Graduado em Direito pela Faculdade de São Lourenço, pós-graduado em Direito Público pela Faculdade de São Lourenço, em Direito Tributário pela Fundação Getúlio Vargas, Direito Ambiental e Urbanístico pelo Centro Anhanguera de Promoção e Educação Social e mestre em Direito - linha Constitucionalismo e Democracia - pela Faculdade de Direito do Sul de Minas Gerais. E-mail:wagnersflb@gmail.com

${ }^{3}$ Possui graduação em Direito pela Universidade de Taubaté (2001), especialista em Processo Civil, Direito Civil e Direito Público. Atualmente é professor da Faculdade de Direito de Varginha (FADIVA) e na Universidade Vale do Rio Verde (UNINCOR), no curso de graduação e pós-graduação, e advogado com escritório próprio. Mestrando em Letras na Universidade Vale do Rio Verde (UNINCOR). É parecerista da área de Direito Público, com ênfase na Administração Pública. E-mail: daheredaher@hotmail.com
} 


\section{INTRODUÇÃO}

Nos últimos anos constatamos que o mundo ficou pequeno. E não apenas no sentido literal da palavra "pequeno", mas também no seu sentido figurado. Ficou pequeno não apenas porque $\mathrm{o}$ desenvolvimento dos meios de transporte encurtou distâncias, mas também porque o desenvolvimento dos meios de comunicação fez com que, em minutos, saibamos de um fato que ocorreu do outro lado do mundo.

Tal encurtamento tem seu lado bom e seu lado ruim. O lado bom é que podemos ter contato com várias culturas, com formas diferentes de ver o mundo, podemos ir a locais que antes nem poderíamos imaginar. $\mathrm{O}$ lado ruim é que, ao tomar contato, conhecemos também as mazelas e a pequenez humana.

Este estudo pretende conhecer o instituto da intervenção humanitária que foi criado para permitir que um país intervenha, inclusive militarmente, em outro para impedir que os direitos humanos sejam desrespeitados. $\mathrm{O}$ que se pretende compreender é o motivo pelo qual um instrumento, aparentemente tão útil, não é considerado tão bom quanto deveria ser.

Para tanto, será analisado o caso concreto e atual do Iraque em que o Estado Islâmico do Iraque e Levante (EIIL), movimento jihadista dirigido por $\mathrm{Abu} \mathrm{Bakr}$ al-Bagdadi que promove atos de violência em prol de sua causa, e faz forte propaganda disso, a fim de verificar se a intervenção realizada no território realmente tem fins humanitários ou se tem outros objetivos.

Inicialmente irá se apresentar um pequeno histórico sobre o Iraque na modernidade, em que se dará especial atenção ao surgimento EIIL. Posteriormente será estudada a intervenção humanitária, conceito, relação com a soberania do país, definição normativa, diretrizes elaboradas pela International Commission on Intervention and State Sovereignty e seus reflexos no instituto da intervenção. Por fim, o caso concreto estudado será retomado com o objetivo de confirmar se a intervenção humanitária seria ou não o melhor caminho, não apenas para o Iraque, mas também para a Síria que acaba de se tornar notícia em todo mundo por conta de seus cidadãos que, em elevado número, estão deixando o país e acabam morrendo pelo caminho ou terminam em condições miseráveis ao se tornarem refugiados.

\section{IRAQUE - CONTEXTO HISTÓRICO E CENÁRIO ATUAL:}

O principal aspecto sobre o Iraque que deve ser conhecido antes de todos os outros é que o país detém $9 \%$ das reservas mundiais de petróleo (O que motiva..., 2014). Trata-se, portanto, de área de alto interesse dos países que pretendem dominar a produção mundial, entre eles, os Estados Unidos. 
O Estado Iraquiano como conhecemos hoje foi criado em 1932 quando se tornou independente da Inglaterra. Inicialmente era uma monarquia que teve como primeiro governante o rei Farouq, da família real Hashemita de Meca, apenas alcançando à República em 1958 (O que motiva o conflito no Estado iraquiano, 2014).

Em 17 de Julho de 1968 ocorre um golpe de estado e chega ao poder o partido Baath (Renascimento, em árabe) inaugurando um regime oligárquico-militar. Anos mais tarde, em 15 de Julho de 1979, Saddam Hussein alcançaria a liderança do país (O que motiva o conflito no Estado iraquiano, 2014).

O país é composto de maioria árabe e minoria de curdos, entre outros grupos, e a população é majoritariamente islâmica divididos em xiitas e sunitas. Os xiitas são o ramo mais ortodoxo do Islã e acreditam que a adoção de uma postura mais rígida na vida levaria ao retorno do último descendente de Maomé para governar a humanidade. Já a maioria sunita é considerada mais moderada na interpretação das escrituras sagradas, além serem mais conciliadores e pragmáticos na política (G1, Entenda as razões que levaram a um novo conflito no Iraque, 2014).

O Iraque é uma construção política feita de acordo com as conveniências de sua antiga potência ocupante, a GrãBretanha. O próprio nome do país é derivado de uma região perto de Basra, no sul do país, e nada significa para a maioria de seus habitantes. No norte, os curdos grupo étnico persa, de maioria sunita e religião islâmica sunita ou xiita, presente também no Irã, na Síria e na Turquia _ sonham em estabelecer um Estado próprio, o Curdistão. Os árabes xiitas concentram-se nas regiões mais populosas do sul. Os árabes sunitas estão estabelecidos na região central do país. Do ponto de vista étnico e religioso, o atual regime é mais democrático do que o anterior, no qual predominavam os árabes sunitas do clã de Saddam. Ainda assim, poucos progressos foram feitos no sentido de incorporar todos os setores da população no governo e no Estado (O que motiva o conflito no Estado iraquiano, 2014).

Em 1980 Saddam Hussein trava uma guerra contra o Irã e em 1990 ele invade o Kuwait com o objetivo de controlar suas reservas de petróleo. A derrota nesta última batalha foi humilhante por conta da intervenção americana que se uniu a outros 28 países para derrota-lo, mas os americanos não tiraram o ditador do poder, simplesmente saíram do país invadido e deixaram a queda de Saddam por conta do povo iraquiano. Durante todo seu, governo Saddam Hussein submeteu seu povo à repressão e à pobreza, a despeito da abundância de petróleo da região, mesmo assim o povo sofrido não teve forças para retirá-lo do poder. A forte ditadura instalada no país não deu brecha para atuação popular.

O início dos anos 90 também foi profundamente abalado pela invasão do Iraque ao Kuwait, comandada por Saddam Hussein, motivado pela baixa do preço do petróleo em razão da venda do 
produto a preços mais baixos do que a cota estipulada pela OPEP (Organização dos Países Exportadores do Petróleo). A complexidade das questões econômicas, aliada ao "braço deferro" de Saddam, fez com que o Iraque, mesmo diante do embargo comercial que lhe foi decretado pela ONU, anexasse o país vizinho, provocando a morte de milhares de pessoas até o fim da ocupação, por obra da "Operação Tempestade no Deserto", constituída por forças coligadas de mais de 30 países, liderados pelos EUA (Medeiros, 2006, p. 97).

Em 11 de Setembro de 2001 os ataques aos Estados Unidos mostraram ao mundo a vulnerabilidade do gigante que, em reação, resolveu eliminar todo e qualquer inimigo espalhado pelo mundo antes que eles pudessem colaborar com os terroristas. Primeiro ocorreu o ataque ao regime Talibã no Afeganistão, mas em 2003 novamente as atenções americanas se voltam para o Iraque e para Saddam Hussein, agora acusado de fabricar e manter armas de destruição em massa que poderiam ser entregues a terroristas (Bush já está em Guerra, 2003). Tal fato nunca foi provado e o clima de vingança apenas colaborou para um conflito armado sem sentido.

Desta vez os americanos chegaram a Bagdá e depuseram Saddam Hussein que fugiu e foi encontrado tempos depois escondido em uma toca, posteriormente fora condenado a pena de morte e enforcado em 30 de Dezembro de 2006 (Schelp, 2003).
O objetivo dos Estados Unidos ao depor o ditador iraquiano era construir no país um exemplo de democracia que pudesse servir de exemplo para os países da região (Schelp, 2003). Mas o plano não deu certo e a invasão foi desastrosa custando milhares de vidas e encerrando-se apenas em 2011. Com o final da guerra os xiitas (encabeçados pelo partido Dawa) (O que motiva o conflito no Estado iraquiano, 2014) passaram a governar o país em substituição aos sunitas que estavam acostumados ao poder, uma vez que estiveram governando ao lado de Saddam, insatisfeitos eles iniciaram protestos pacíficos em 2012. Foi quando ocorreu a aproximação de sunitas e o grupo Estado Islâmico (EI) (Entenda as razões que levaram a um novo conflito no Iraque, 2014).

O Estado Islâmico (EI), nome do grupo que tem espalhado o terror na região, se diz sunita, porém seus membros têm adotado uma postura radical e violenta para alcançar seu objetivo: criar um estado sunita em um território na fronteira do Iraque com a Síria, governado com base na lei islâmica, a Sharia.

Os sunitas dominaram o Iraque até a invasão dos Estados Unidos e a queda de Saddam Hussein - que fez com que se instalasse um governo xiita. Insatisfeitos, eles começaram protestando pacificamente em 2012, mas com poucos resultados. A marginalização dos cerca de 5 milhões de sunitas iraquianos fez com que eles passassem a ser mais simpáticos às ações armadas do EI - antes conhecido como Estado Islâmico do Iraque e Levanta (EIIL ou ISIS, na sigla em inglês). 
Após a retirada das tropas americanas do Iraque em 2011, o grupo, que ganhou força na sua atuação no conflito da Síria e conquistou territórios por lá, passou a avançar sobre o norte iraquiano (G1, Entenda as razões que levaram a um novo conflito no Iraque, 2014).

O Estado Islâmico do Iraque e Levante é um grupo fundamentalista jihadista que surgiu do Estado Islâmico no Iraque, antigo braço iraquiano da Al-Qaeda, é dirigido por Abu Bakr al-Bagdadi (G1, Conheça o Estado Islâmico, grupo radical com milhares de combatentes, 2014) que foi designado "califa de todos os muçulmanos" no dia 29 de Junho de 2014 (Saiba quem é Abu Bakr al-Bagdadi, nomeado 'califa' pelo Estado Islâmico, 2014).

Os membros do EI são chamados de jihadista, nome dado aqueles que promovem a jihad expressão traduzida no Ocidente como "guerra santa". A jihad tem, originalmente, um significado mais espiritual. Porém com o tempo, passou a designar também a luta armada para impor um estado islâmico ou para combater aqueles considerados inimigos do islã (G1, Entenda as razões que levaram a um novo conflito no Iraque, 2014).

Abur Bakr nasceu em 1971 em Samara, norte de Bagdá, e já teria sido ficado detido em um campo americano. Um de seus pseudônimos seria Abu Duaa e sua morte foi equivocadamente anunciada pelos EUA em 2005. Ele passou a ser considerado terrorista em outubro de 2011. Possui personalidade misteriosa e seu rosto somente se tornou conhecido este ano quando foi divulgada uma foto sua em preto e branco (em Janeiro de 2014) (Saiba quem é Abu Bakr al-Bagdadi, nomeado 'califa' pelo Estado Islâmico, 2014).

O EIIL anunciou a criação de um califado (Saiba quem é Abu Bakr al-Bagdadi, nomeado 'califa' pelo Estado Islâmico, 2014) entre Iraque e Síria com o objetivo de restabelecer o estado islâmico que deixou de existir há quase um século (Saiba quem é Abu Bakr al-Bagdadi, nomeado 'califa' pelo Estado Islâmico, 2014), na época do profeta Maomé. A partir deste momento o EIIL passou a ser chamado Estado Islâmico (EI) e pediu a todos os muçulmanos que jurem lealdade a seu chefe, o califa (Entenda o que é um califado, 2014).

O EI atua com extrema violência (decapitações, crucificações, sepultamento de vítima viva e apedrejamento), provocando horror até mesmo em outros grupos radicais, e divulga isso via rede internacional de computadores (Por que o Estado Islâmico utiliza técnicas tão brutais?, 2014). O uso deste meio é uma decisão consciente de aterrorizar o inimigo, ou seja, não se recorre à teologia para justificar os crimes. A tática de comunicação agressiva do EI tem por objetivo impressionar a opinião pública e cooptar jovens recrutas sunitas desiludidos ${ }^{1}$ que vêm o grupo como vanguarda poderosa que oferece a vitória e a salvação ${ }^{2}$.

(...) o EI professa ação violenta sem qualquer preceito teórico ou 
teológico e em nenhum momento demonstrou ter um repertório de ideias que sustente e nutra a sua base social. Trata-se de uma máquina de matar alimentada por sangue e armas.

Indo além da doutrina de Bin Laden de que "quando as pessoas veem um cavalo forte e um cavalo fraco, por natureza vão escolher o mais forte", a vitória por meio do terrorismo de al-Baghdadi indica a amigos e inimigos que este é um "cavalo vencedor".

"Saia do caminho ou você será esmagado; junte-se a nós e faça história" parece ser o lema do EI. Evidências cada vez mais fortes mostram que, nos últimos meses, centenas senão milhares de antigos e obstinados inimigos do EI, como a Frente al-Nusra e a Frente Islâmica, responderam ao chamado de al-Baghdadi (Por que o Estado Islâmico utiliza técnicas tão brutais?, 2014).

O fato é que tais inserções em mídia fazem com que grupos humanitários pressionem pedindo providências para o fim do massacre, inclusive por meio de intervenções militares, em especial a americana (O que motiva o conflito no Estado iraquiano, 2014). É neste ponto que passamos ao assunto principal deste estudo que são as intervenções humanitárias.

\section{INTERVENÇÃO HUMANITÁRIA}

Em regra, um país não pode intervir no outro (nem econômica, nem política, nem militarmente), este é o chamado princípio da não-intervenção expressamente descrito no artigo $2^{\circ} \$ 4^{\circ}$ da Carta da ONU que, além de proteger a soberania, aponta os limites exteriores da influência que um Estado pode exercer em relação a outro Estado, ou seja, protege-se a soberania de um Estado ao constranger a soberania dos outros Estados e vice-versa (Spieler, 2007).

\begin{abstract}
Nesse contexto, pode-se afirmar que o reconhecimento por cada Estado soberano da soberania do outro na sociedade internacional é essencial para sua coexistência. $\mathrm{O}$ direito de um Estado à soberania pressupõe, assim, que os outros Estados têm o dever de respeitar tal direito, implicando, por conseguinte, em abster-se de intervir nos assuntos domésticos de outro Estado. (Spieler, 2007)
\end{abstract}

Porém, recentemente, passou-se a considerar que nem mesmo a soberania, base do Estado Moderno, não é conceito absoluto uma vez que hoje se permitem formas de intervenção pelos seguintes motivos: (i) quando a intervenção é realizada mediante convite do Estado que está sofrendo a interferência; (ii) quando tem por objeto a defesa de um Estado ameaçado; (iii) quando tem por finalidade os direitos de pessoas estrangeiras que estão sob a autoridade de um governo opressivo. Desta última forma surge a intervenção por motivos humanitários, ou seja, a intervenção que objetiva a garantia dos direitos humanos (Spieler, 2007).

$\mathrm{O}$ conceito de intervenção ${ }^{3}$ humanitária começa a ser delineado no decorrer da Guerra Fria quando se observa que as ações desarmadas de assistência humanitária não são suficientes para resolver a situação de populações que necessitam de auxílio, em países em situação de crise ou 
não. Ela consiste em mitigar o conceito de soberania estatal, permitindo até mesmo o uso da força, a fim de proteger indivíduos que estejam sofrendo agressões a seus direitos humanos o que valoriza a vida humana acima de qualquer instituição política (Vaz, 2010, p. 101).

Tradicionalmente, intervenção tem sido definida em termos metafóricos de uma fenda coercitiva nas paredes de um castelo soberano. Tal fenda viola a norma cardinal da soberania e seu corolário principal da nãointervenção. Esse fato está cristalizando no direito costumeiro internacional e codificado no art. $2^{\circ}$ da Carta das Nações Unidas, proibindo as Nações Unidas de intervir nos assuntos que são essencialmente de jurisdição interna de qualquer Estado (Souto \& Dantas, 2009).

O problema é que a falta de definição normativa e precisa do que seria intervenção humanitária pode levar a abusos no uso do instituto por motivos políticos ou econômicos. Por conta disso surge a "Responsabilidade de Proteger" que, além de estabelecer diretrizes para o uso da força a fim de proteger vidas humanas e direitos humanos, pretende reconciliar o conceito de soberania e a proteção dos direitos humanos. Como ainda é um instrumento em implementação ainda não se pode afirmar com segurança que será a solução para evitar abusos (Jubilut, 2010, p. 161).

O problema do abuso faz com que alguns acreditem que essa ação sempre será uma arma que os fortes utilizarão contra fracos. A seletividade de responsabilidades devem ser destacada, devido ao fato da contraposição existente entre um princípio moral e o interesse nacional.

Segundo o que nos ensina Chris Brown: "O problema principal, neste caso, é que a intervenção humanitária sempre será baseada em predileções culturais daqueles quem tem o poder de agir". Portanto, falta um consenso sobre quais princípios deveriam governar o direito de intervenção (Souto \& Dantas, 2009).

A primeira diretriz estabelecida pela comissão (International Commission on Intervention and State Sovereignty - ICISS) criada pela Organização das Nações Unidas (ONU) especialmente para discutir o assunto foi a alteração do conceito de soberania como um direito absoluto para soberania como responsabilidade. Trata-se de estabelecimento de limites à soberania estatal o que privilegia a soberania individual (Jubilut, 2010, p. 161).

A segunda diretriz envolve a forma como a intervenção humanitária é encarada. Anteriormente, era baseada na soberania do indivíduo o que acabava por flexibilizar o conceito de soberania estatal. Pensava-se que tal intervenção era um direito e não uma permissão para intervir, o que se aproximava muito mais da ideia de ingerência do que de intervenção. Com o trabalho da ICISS, percebeu-se que o foco da ação deve ser o interesse dos beneficiados e não $\operatorname{do}(\mathrm{s})$ Estado(s) que estaria(m) conduzindo a ação. Em decorrência disso, a permissão para a intervenção humanitária passa a ser não 
apenas repressiva como também preventiva do conflito $^{4}$, o que permitiria o diálogo sobre certas situações de crise antes que ela avançasse irremediavelmente para a intervenção militar (Jubilut, 2010, p. 162).

Tais diretrizes tendem a transformar a intervenção humanitária em um instrumento realmente capaz de beneficiar as nações que precisem dela sem permitir abusos das outras nações. $O$ fato é que a intervenção humanitária deve ser reservada apenas para casos excepcionais a fim de evitar que uma intervenção se torne uma ingerência política, econômica ou militar.

(...) é preciso demonstrar a revolta moral diante das guerras contemporâneas e da maneira pela qual são estas conduzidas, buscando modo de as ver legitimadas. É preciso lançar outro olhar sobre os discursos destinados a conquistar a adesão dos povos e dos indivíduos e fazer esforço de desmistificação: "a defesa dos direitos do homem, o dever de intervenção humanitária, a luta contra o terrorismo, são hoje invocados para justificar ingerência de mão única, que vai ao ponto de advogar a necessidade de guerras preventivas. Ora sob o manto de argumentos éticos, são imperativos políticos e econômicos, que se escondem." Para se perceber, em suma, "é o imperialismo que rege esse tipo de iniciativa" (Casella, 2008, pp. 1212-1213).

Retomando o caso concreto em análise é importante lembrar que os Estados Unidos têm interesse econômico no petróleo da região iraquiana e fará de tudo para não perder seu controle. Há também que se considerar que a indústria bélica americana se beneficia muito com o conflito uma vez que vende seu produto para os dois lados em guerra e, a grande preocupação atual, a necessidade de se preservar vidas americanas uma vez que muitas vidas foram ceifadas no último conflito e isso não ficou bem diante da opinião pública, não impede que a guerra ocorra porque hoje existem os chamados drones, que são veículos aéreos não tripulados que permitem ataques sem ameaça a vida dos pilotos.

Há que se reconhecer que o Iraque precisa de ajuda, porém, é discutível que tal ajuda deva ser uma intervenção humanitária. Melhor seria o fortalecimento dos Estados Sírio e Iraquiano a fim de que eles mesmos solucionassem seus conflitos internos de forma que sua democracia (ou qualquer outra forma de governo escolhida por eles), cultura e religião saíssem valorizadas. O problema é que isso pode acarretar menor acesso ao petróleo da região, o que os Estados Unidos e outros países tanto do oriente como do ocidente não querem que ocorra.

\section{CONSIDERAÇÕES FINAIS}

Depois de todo o exposto pudemos concluir que o Iraque é um país massacrado por conta dos interesses econômicos em seu território. Desde sua fundação e, especialmente na época de Saddam Hussein, o 
país não teve o direito de resolver seus conflitos internos sem a intervenção de outras nações. Tal aspecto fez com que seu amadurecimento como Estado não fosse satisfatório.

A má resolução dos conflitos internos fez com que surgisse um grupo jihadista chamado Estado Islâmico do Iraque e Levante (EIIL), antigo braço iraquiano da Al-Qaeda, dirigido por Abu Bakr al-Bagdadi que foi designado "califa de todos os muçulmanos", oportunidade em que o EIIL passou a se chamar apenas Estado Islâmico (EI).

O EI atua com extrema violência (decapitações, crucificações, sepultamento de vítima viva e apedrejamento), provocando horror até mesmo em outros grupos radicais, e divulga isso via rede internacional de computadores. A tática de comunicação agressiva do EI tem por objetivo impressionar a opinião pública e cooptar jovens recrutas desiludidos. Tal atuação fez com que grupos humanitários atuassem para pedir providências para o fim do massacre, inclusive por meio de intervenções militares.

Discutiu-se, então, o conceito de intervenção humanitária, o desenvolvimento do instituto e se o que acontece no Iraque é ou não intervenção humanitária e se este seria o melhor caminho.

Intervenção humanitária consiste em mitigar o conceito de soberania estatal, permitindo até mesmo o uso da força, a fim de proteger indivíduos que estejam sofrendo agressões a seus direitos humanos, o que valoriza a vida humana acima de qualquer instituição política.

O problema é que a falta de definição normativa do que seria intervenção humanitária levou a abusos no uso do instituto por motivos políticos ou econômicos. Por conta disso surge o conceito da "Responsabilidade de Proteger" que, além de estabelecer diretrizes para o uso da força a fim de proteger vidas humanas e direitos humanos, pretende reconciliar o conceito de soberania e a proteção dos direitos humanos.

A partir disso concluiu-se que a intervenção que ocorre atualmente no Iraque usa o discurso humanitário para camuflar interesses econômicos. Há que se reconhecer que o Iraque precisa de ajuda, porém, é discutível que tal ajuda deva ser uma intervenção humanitária. Melhor seria o fortalecimento dos Estados Sírio e Iraquiano a fim de que eles mesmos solucionassem seus conflitos internos de forma que sua democracia (ou qualquer outra forma de governo escolhida por eles), cultura e religião saiam valorizadas.

\section{REFERÊNCIAS}

Bush já está em guerra. Veja. 05 Fev. 2003. P. 62-65. 
CASELLA, Pedro Borba. Fundamentos do Direito Internacional Pós-Moderno. São Paulo. Quartier Latin, 2008.

Conheça o EIIL grupo jihadista radical com milhares de combatentes. G1. Ago. 2014. Disponível em: <http://g1.globo.com/mundo/noticia/2014/06/ conheca-o-eiil-grupo-jihadista-radical-commilhares-de-combatentes.html> Acesso em: 01/08/2015.

Entenda as razões que levaram a um novo conflito no Iraque. G1. Ago. 2014. Disponível em:

<http://g1.globo.com/mundo/noticia/2014/08/ entenda-razoes-que-levaram-um-novoconflito-no-iraque.html> Acesso em: 02/08/2015.

Entenda o que é um califado. G1. Ago. 2014. Disponível em: <http://g1.globo.com/mundo/noticia/2014/06/ entenda-o-que-e-um-califado.html> Acesso em: 01/08/2015.

ESPINOSA, Ángeles. Uma novela contra o califado. El País. Dubai. Nov 2014. Disponível em: <http://brasil.elpais.com/brasil/2014/11/25/int ernacional/1416955658_341416.html> Acesso em: 01/08/2015.
GHIROTTO, Edoardo. Contrapropaganda tenta dissuadir jovens de se unir ao EI. Veja. Disponível em: <http://veja.abril.com.br/noticia/mundo/contr apropaganda-tenta-dissuadir-jovens-de-sejuntar-ao-ei> Acesso em: 10/08/2015.

JUBILUT, Liliana Lyra. Não Intervenção $e$ Legitimidade Internacional. São Paulo. Saraiva 2010.

MEDEIROS, Ana Letícia Barauna Duarte. Intervenção humanitária e direito internacional humanitário: paradoxos jurídico-políticos do século XXI. Revista da Faculdade de Direito da UFPR. P. 95-108. Disponível em: <http://ojs.c3sl.ufpr.br/ojs2/index.php/direito/ article/view/9417> Acesso em 07/08/2015.

O que motiva o conflito no Estado iraquiano. ZH notícias. Ago. 2014. Disponível em: $<$ http://zh.clicrbs.com.br/rs/noticias/noticia/20 14/08/o-que-motiva-o-conflito-no-estadoiraquiano-4572293.html> Acesso em: $15 / 08 / 2015$.

Por que o Estado Islâmico usa técnicas tão brutais? G1. Ago. 2014. Disponível em: <http://g1.globo.com/mundo/noticia/2014/09/ por-que-o-estado-islamico-utiliza-tecnicastao-brutais.html> Acesso em: 17/08/2015.

Saiba quem é Abu Bakr Al Bagdagi designado califa pelo EIIL. G1. Ago. 2014. 
Disponível

em:

<http://g1.globo.com/mundo/noticia/2014/06/

saiba-quem-e-abu-bakr-al-bagdadi-designado-

califa-pelo-eiil.html> Acesso em: 08/08/2015.

SOUTO, Eliézer Queiroz de; DANTAS,

Dandara Viégas. Intervenção humanitária e a questão da soberania nacional no atual contexto da sociedade internacional. Âmbito Jurídico, Rio Grande do Sul, XII, n. 65, jun 2009. Disponível em: <http://www.ambitojuridico.com.br/site/index.php?artigo_id=636 5\&n_link=revista_artigos_leitura>. Acesso em 20/08/2015.

SPIELER, Paula Bartolini. A indeterminação do conceito de intervenção humanitária. Reflexo no caso Timor Leste. Dissertação de Mestrado PUC-Rio orientadora: Mônica Herz.

Rio de Janeiro 2007. Disponível em: $<$ http://www.maxwell.vrac.puc-

rio.br/10564/10564_1.PDF> Acesso em:

01/08/2015.

VAZ, Anelise Gomes. O Estado da Arte das Intervenções Humanitárias. Revista Eletrônica Dos Pós-Graduandos em Sociologia Política da UFSC. V. 7 - n. 1/2 janeiro-dezembro/2010. P. 98-112. Disponível em: Shttps://periodicos.ufsc.br/index.php/emtese/a rticle/view/1806-5023.2010v7n12p98>.

Acesso em: 01/08/2015. 